\title{
A INTERAÇÃO ENTRE LIVRO DIDÁTICO DE LÍNGUA ESTRANGEIRA E A FORMAÇÃO DO CIDADÃO PROPOSTA NOS PCN - LE ${ }^{1}$
}

\author{
THE INTERACTION BETWEEN FOREIGN LANGUAGE TEXTBOOKS AND THE \\ CITIZENSHIP EDUCATION SUGGESTED BY THE NATIONAL CURRICULUM \\ GUIDELINES
}

Submetido em: 19- 06-2011

Publicado em:21-12- 2012

Leonice Passarella dos Reis2 Mestrado em Letras (Inglês e Literatura Correspondente) (Conceito CAPES 5). Universidade Federal de Santa Catarina, UFSC, Brasil leonicepr@gmail.com

\section{Resumo:}

Este artigo tem como objetivo investigar como a questão da formação do cidadão é abordada por dois livros didáticos (LD) disponibilizados para o ensino de inglês como língua estrangeira moderna em 2011 pelo Governo Federal. A pesquisa se fundamentou nos princípios e concepções norteadores dos PCN - LE para o Ensino Fundamental. A análise dos dados angariados através de dois checklists demonstrou que (1) os dois LD fomentam o tema cidadania e (2) suas atividades promovem, em níveis diferentes, o engajamento discursivo do aprendente. Cabe à professora, professor e escola tomarem ações e práticas pedagógicas que potencializem essas atividades para a promoção mais completa da formação do cidadão, agente crítico no mundo social.

Palavras-chave: Livro didático de língua estrangeira. Cidadania. Parâmetros Curriculares Nacionais.

\begin{abstract}
:
This article sets out to investigate the way citizenship education is tackled in two textbooks, which were made available by the Federal Government for the teaching and learning of English as a Foreign Language in 2011. The principles supporting this research are the ones guiding the National Curriculum Guidelines for foreign language in elementary school. The analysis of the data gathered through the use of two ckecklists showed that (1) both books include the topic and (2) their activities trigger, in different levels, the discursive engagement of students. It seems to be up to the teachers and schools to take actions and pedagogical practices towards the optimization of those activities in order to offer a more complete education for active citizenship.
\end{abstract}

Keywords: Foreign language textbooks. Citizenship. National Currriculum Guidelines.

\section{INTRODUÇÃO}

"A cidadania é tarefa que não termina. A cidadania não é como um dever de casa, onde (sic) faço a minha parte, apresento e pronto, acabou. Enquanto

\footnotetext{
${ }^{1}$ Artigo escrito como trabalho final em cumprimento dos requisitos da disciplina LIN4100-24 Linguística Aplicada e Ensino de Língua Estrangeira, oferecida pelo Programa de Pós-Graduação em Linguística da UFSC, ministrada pela Prof $^{\mathrm{a}} \mathrm{Dr}^{\mathrm{a}}$ Maria Inêz Probst Lucena.
}

Work. pap. linguíst., 13(1): 40-60, Florianópolis, jan.jun,2012 
seres inacabados que somos, sempre estaremos buscando, descobrindo, criando e tomando consciência mais ampla dos direitos. Nunca poderemos chegar e entregar a tarefa pronta, pois novos desafios na vida social surgirão, demandando novas conquistas e, portanto, mais cidadania." (DALLARI, 1998, apud DHNET, 2010)

A Lei de Diretrizes e Bases da Educação Nacional de dezembro de 1996, art. 32, estabelece, como objetivo da educação do ensino fundamental, a formação básica do cidadão mediante

(1) "o desenvolvimento da capacidade de aprender", (2) "a compreensão do ambiente natural e social, do sistema político, da tecnologia, das artes e dos valores que fundamentam a sociedade", (3) "o desenvolvimento da capacidade de aprendizagem, em busca de conhecimentos e habilidades e da formação de atitudes e valores", e (4) "o fortalecimento dos vínculos familiares, dos laços de solidariedade e de tolerância recíproca" (BRASIL, 1996, p. 12).

Em consonância com a ideia acima exposta, lê-se nos Parâmetros Curriculares Nacionais de Língua Estrangeira para o Ensino Fundamental (BRASIL, 1998 - doravante PCN - LE), que a escola tem de estar comprometida com a formação de cidadãos. Os PCN destacam ainda que, embora durante muito tempo, o ensino de Língua Estrangeira, doravante LE, não fosse visto como participante nessa formação e embora ocupasse uma posição de desprestígio no quadro curricular, a aprendizagem de LE permite ao aprendente autoperceberse como ser humano e como cidadão. A disciplina de LE desencadeia essa percepção principalmente ao promover o engajamento discursivo ${ }^{2}$ do aprendente durante o seu processo de aprendizagem. Dentre os conteúdos sugeridos pelos PCN para o ensino e a aprendizagem de LE, encontram-se os que estão diretamente ligados à questão da construção da cidadania. Ainda, os PCN propõem que as atividades que abordam esses conteúdos devam permitir que o aprendente engaje-se discursivamente e sinalizam a necessidade de elaboração de material didático adequado para esse fim.

Com relação ao material didático, é senso comum que o livro didático, doravante LD, é um dos recursos amplamente utilizados nas diversas áreas do conhecimento escolar. Até 2011, o governo não havia ainda disponibilizado o LD de língua inglesa para as escolas públicas de ensino fundamental e médio, o que dificultou a sua adoção nessas escolas devido ao custo deste material, sendo o LD mais utilizado em escolas privadas (PINTO; PESSOA, 2009). O PNLD (Programa Nacional do Livro Didático), que, dentre outros trabalhos, realiza avaliações de LD nas várias áreas do conhecimento com o intuito de auxiliar o professor ou a escola na decisão quando da adoção de um determinado LD, disponibilizou, em 2010, a primeira avaliação para livros de LE, a serem adotados em 2011. Um total de 26 coleções nacionais de LD de língua inglesa foi analisado pelo Programa e duas foram escolhidas como opção de adoção em 2011 (Keep in Mind e Links: English for Teens) e são parte do corpus deste trabalho ${ }^{3}$.

\footnotetext{
${ }^{2}$ Engajamento discursivo diz respeito à capacidade do aluno de se envolver e de envolver os outros no discurso (BRASIL, 1998, p. 19).

${ }^{3}$ Duas línguas estrangeiras receberam LD em 2011: inglês e espanhol. Optei por focalizar o LD de língua inglesa por (1) ser a língua que leciono e também (2) pela visão massificada do inglês como língua internacional, que pode facilitar o acesso e a comunicação em nível transnacional, importante para a formação do cidadão do mundo.
}

Work. pap. linguíst., 13(1): 40-60, Florianópolis, jan.jun,2012 
Quanto ao uso do LD, Pereira (2007), ao conduzir uma pesquisa sobre leitura, reporta que os professores se sentem pressionados pela Escola e pelos pais a utilizarem o LD quando ele não é distribuído pelo Governo Federal, haja vista a demanda de investimento financeiro por parte dos pais para a sua aquisição. Magno e Silva (2009) comentam não apenas acerca dessa insistência, mas também sobre a pressão de que seja realizada a utilização integral do LD, sem ignorar unidades ou determinado conteúdo. Associados a essa pressão por parte da comunidade escolar, estão outros fatores como falta de tempo (BORTONI-RICARDO, 1998) e de recursos (PEREIRA, 2007) por parte dos professores para investirem na elaboração ou agrupamento de outros recursos para utilização em aula, o que acaba levando-os a se renderem à utilização do LD.

À luz do contexto acima exposto, é possível supor que tais coleções estejam sendo amplamente utilizadas nas salas de aula de língua inglesa desde 2011. Refletir sobre como a cidadania é tratada nessas coleções me parece importante para auxiliar a prática docente, principalmente em um momento em que as coleções estão sendo utilizadas pelos professores pela primeira vez.

Assim, tendo em vista o disposto nos parágrafos acima, o presente artigo tem como objetivo refletir sobre como as duas coleções propostas pelo PNLD incluem assuntos e atividades que possam auxiliar no processo de construção da cidadania e formação do cidadão. O artigo está dividido em mais quatro seções: referencial teórico, metodologia, resultados e discussão e considerações finais.

\section{REFERENCIAL TEÓRICO}

Esta seção tem como objetivo situar o leitor acerca de alguns assuntos considerados importantes para esta pesquisa, quais sejam: cidadania, linguagem, ensino e aprendizagem e engajamento discursivo, assim como revisar alguns estudos que discutem a análise de LD de LE.

\subsection{Cidadania}

O termo "cidadania" pode ter significados variados. Vieira (2005) explica que, "para os conservadores", só é considerado como sendo cidadão aquele que é nacional de um determinado país, ou seja, que lá nasceu. Em contrapartida, o autor destaca que visões mais democráticas buscam a dissociação de nacionalidade e cidadania. Sob esse prisma, a "cidadania teria uma proteção transnacional, como os direitos humanos" (VIEIRA, 2005, p. 31) e poder-se-ia participar de/ e pertencer a uma comunidade política independentemente da nacionalidade. $\mathrm{O}$ autor aponta algumas questões nacionais, tais como pobreza, danos ambientais, desemprego, entre outras, que passaram a ser transnacionais e é neste contexto que o novo conceito de cidadão se insere: "o conceito de cidadão do mundo, de cidadania planetária, que vem sendo paulatinamente construída pela sociedade civil de todos os países, em contraposição ao poder político do Estado e ao poder econômico do mercado" (VIEIRA, 2005, p. 32). Esse conceito de cidadania, trazido por Vieira (2005), remete-nos à importância de se aprender uma LE para o exercício da cidadania. A LE é um meio de acesso a essas questões apontadas pelo autor em contextos internacionais, permitindo compará-las com aquelas da realidade nacional. A reflexão sobre tais questões da experiência humana, por sua vez, permite o entendimento de um mundo pluralizado e do papel que se tem como cidadão de um determinado país e do mundo (BRASIL, 1998, p. 67).

Work. pap. linguíst., 13(1): 40-60, Florianópolis, jan.jun,2012 
Dois dos dez objetivos gerais apresentados para o ensino fundamental pelos PCN - LE (BRASIL, 1998) fazem menção à cidadania, e os objetivos do ensino e aprendizagem de LE estão direta e indiretamente ligados ao assunto. Os objetivos estão alicerçados na concepção de cidadania "como participação social e política, assim como exercício de direitos e deveres políticos, civis e sociais" (BRASIL, 1998, p. 7). À luz desta concepção, o cidadão é aquele que pratica, diariamente, a solidariedade, a cooperação e o repúdio às injustiças, "respeitando o outro e exigindo para si o mesmo respeito" (BRASIL, 1998, p. 7).

Os assuntos de cidadania pautados nos PCN - LE verificados na análise são:

- Pluralidade cultural: Valores e costumes de outras culturas e da sua própria cultura.

- Percepção de suas próprias características, capacidades, limitações, e respeito às do outro (diferenças, autopercepção, da sua realidade e percepção do outro).

- Inglês como língua hegemônica, desigualdades entre países e grupos sociais.

- Preocupação com a saúde (incluindo diversão e segurança).

- Trabalho e consumo: oportunidades e questões relacionadas ao trabalho e ao consumo exacerbado.

- Valorização das relações entre as pessoas.

- Respeito aos direitos humanos, às várias etnias, aos idosos, aos portadores de necessidades especiais, aos homossexuais, aos falantes de uma variedade não hegemônica.

- Meio ambiente: preservação do meio ambiente e respeito aos animais.

- Orientação sexual: percepção do corpo como fonte de prazer e consciência da pluralidade de expressão da sexualidade humana.

\subsection{Linguagem, ensino e aprendizagem nos LD}

Os papéis e as funções assumidos pelo LD dependem da concepção "de linguagem e do processo ensino/aprendizagem que cada autor possui, além de dependerem do uso que dele se deseja fazer" (RAMOS, 2009, p. 176). A concepção de linguagem e de processo de ensino e aprendizagem que orientam este estudo são os apresentados pelos PCN (BRASIL, 1998).

A concepção de linguagem que norteia esse documento é a de natureza sociointeracional. Sob essa perspectiva, a construção do significado se dá socialmente (em determinado momento e local), através da interação entre duas partes. Assim, a linguagem é utilizada para ação no mundo social.

Quanto ao ensino e aprendizagem, os PCN indicam que, embora as teorias behaviorista e cognitivista tenham contribuído para a compreensão do processo de ensino e aprendizagem, "cada vez mais tende-se a explicar a aprendizagem como um fenômeno sociointeracional" (BRASIL, 1998, p. 57). À luz do sociointeracionismo, o foco do processo de ensino e aprendizagem está nas interações que o permeiam: professor/aluno e aluno/aluno ${ }^{4}$. Os processos cognitivos se originam dessas interações entre os indivíduos que se relacionam no mundo social, dentro de um contexto histórico, cultural e institucional (BRASIL, 1998, p. 57).

De acordo com os PCN, essas concepções levam à compreensão da aprendizagem (1) como forma de coparticipação social, ou seja, através da participação de alguém com o outro em contextos de ação, e (2) como construção de conhecimento compartilhado, realizada através das interações professor/aluno e aluno/aluno. A presente pesquisa parte do pressuposto de que essas concepções estejam presentes também nos LD que serão analisados

\footnotetext{
${ }^{4}$ Para exemplos dessas interações, vide Johnson (1995, p. 93-128).
} 
e que as atividades que tais livros propõem ofereçam meios para que essas interações ocorram.

\subsection{Engajamento discursivo}

Engajamento discursivo diz respeito à capacidade do aluno de se envolver e de envolver os outros no discurso (BRASIL, 1998, p. 19). Três tipos de conhecimentos são destacados pelos PCN como formadores do alicerce para este engajamento, quais sejam: o conhecimento sistêmico, o conhecimento de mundo e o conhecimento da organização textual. $\mathrm{O}$ conhecimento sistêmico envolve os conhecimentos léxico-semânticos, morfológicos, sintáticos e fonético-fonológicos, permite que se faça escolhas gramaticalmente adequadas e auxilia na compreensão de um determinado enunciado. $O$ conhecimento de mundo diz respeito ao conhecimento que se tem das coisas do mundo e varia de pessoa para pessoa, dependendo de seu contexto diário e de suas experiências vividas. O conhecimento da organização textual, de textos orais ou escritos, refere-se ao conhecimento de como a informação é organizada para a interação (texto/leitor, locutor/interlocutor etc.).

Todos esses conhecimentos são utilizados por falantes e escritores para a construção do significado que querem comunicar, enquanto os seus ouvintes e leitores

projetam esses conhecimentos na construção do significado. O processo de construção do significado resulta no modo como as pessoas realizam a linguagem no uso e [esse processo de construção do significado] é essencialmente determinado [...] pelo modo como as pessoas agem por meio do discurso no mundo social. (BRASIL, 1998, p. 32) (acréscimo meu)

Em outras palavras, esses conhecimentos são essenciais para a construção da linguagem e a formação do ser discursivo, ativo no mundo social, e a ausência ou o pouco domínio desses conhecimentos pode comprometer o engajamento discursivo do aprendente. Na rotina da sala de aula de LE, através das interações, principalmente aquelas que permitem que o aluno possa se pronunciar, acontecem essas construções de conhecimento e também o ato do aprendente de se engajar discursivamente, o que está relacionado com o seu desenvolvimento como cidadão. (BRASIL, 1998). Com relação a isso, a presente pesquisa busca analisar se esses conhecimentos e interações são desencadeados pelas atividades nos LD, com vistas ao desenvolvimento do cidadão.

\subsection{Estudos sobre LD}

O uso do LD e o seu papel no campo educacional têm sido foco de pesquisas e discussões recentes no contexto nacional e internacional (PINTO e PESSOA, 2009; MAGNO E SILVA, 2009; RICHARDS, 2002 apud RAMOS, 2009; entre outros), problematizando e levantando alguns pontos sobre a sua utilização. Entre os pontos negativos estão: (1) a presença de linguagem não autêntica, (2) a presença de uma visão distorcida do mundo (o mundo ideal é expresso como sendo o real), (3) a incapacidade de atender às necessidades da realidade local, (4) a limitação da criatividade e autonomia do professor e (5) o alto custo para sua aquisição (RICHARDS, 2002 apud RAMOS, 2009). Quanto aos pontos positivos, são destacados: (1) o fornecimento de um programa estruturado e um sumário do conteúdo; (2) a padronização do conteúdo que pode ser trabalhado com turmas diferentes; (3) a qualidade, visto ter sido previamente testado; (4) o acompanhamento de outros recursos instrucionais, como CD-ROM, vídeos etc.; (5) a otimização do tempo do professor na preparação da aula;

Work. pap. linguíst., 13(1): 40-60, Florianópolis, jan.jun,2012 
(6) a possibilidade de servir como meio de capacitação aos professores iniciantes, por oferecer dicas de como abordar cada lição; entre outros (RICHARDS, 2002 apud RAMOS, 2009).

O presente trabalho advoga, em concordância com Ramos (2009), que o LD parece ser mais um "colaborador, uma ferramenta auxiliar" do que "um vilão" e que pode ser visto como "o fio condutor, que proporciona uma certa estrutura de aprendizagem" (MAGNO E SILVA, 2009, p. 74). Portanto, a sua análise cuidadosa é essencial para que o seu uso seja feito de modo a auxiliar e não a dificultar a aprendizagem de LE, e auxiliar no processo de formação de cidadãos proposta pelos PCN.

Segundo Ramos (2009), embora a formação do cidadão raramente apareça como objetivo nos LD, observando o texto introdutório às várias coleções, pode-se encontrar indicações de que elas pretendem abordar o assunto. No entanto, a autora enfatiza que um estudo mais cuidadoso desses livros mostra "que pouco se faz para que isso seja realizado. Como consequência, o professor terá seu tempo [de trabalho] duplicado, caso ele queira e/ou deva atender esse objetivo [de formar cidadãos]" (RAMOS, 2009, p. 188). Apesar de falar sobre o assunto, a autora não discute ou aponta estudos voltados para o LD e a formação do cidadão e não é do meu conhecimento que tais estudos tenham sido realizados ${ }^{5}$.

Em contrapartida, o Guia de Livros Didáticos - PNLD 2011: Língua Estrangeira Moderna, publicado em 2010 pela SEB e Ministério da Educação, traz uma análise dos LD que são foco desta pesquisa: Keep in Mind e Links: English for Teens. O PNLD apresenta os livros como sendo suporte ao planejamento e execução das aulas pelo professor (BRASIL, 2010, p. 9), em consonância com alguns dos pontos positivos levantados e o pensamento que guia a presente pesquisa. Um dos critérios de análise foi verificar se as coleções observam os princípios éticos necessários à construção da cidadania, de acordo com a legislação, as diretrizes e as normas oficiais relativas ao Ensino Fundamental. O Guia indica que as duas coleções propõem atividades (a primeira em número maior do que a segunda) que permitem a reflexão sobre cidadania (BRASIL, 2010). Segundo o Guia, tais atividades podem ser encontradas ao longo das unidades (como na seção Discuss with your classmates) e nos projetos da coleção Keep in Mind e na seção Let's stop and think da coleção Links: English for teens. O presente trabalho procura observar, de forma mais detalhada, como essas atividades e outras atividades que se mostram importantes para o trabalho com o tema cidadania são propostas.

\section{METODOLOGIA}

Esta seção objetiva situar o leitor sobre a metodologia da presente pesquisa, através da apresentação do corpus, dos instrumentos e dos procedimentos de análise.

\subsection{Corpus}

O corpus constitui-se de dois volumes, um da Coleção Keep in Mind e outro da Coleção Links: English for teens, ambos sugeridos pelo PNLD para uso em 2011, nas aulas de inglês

\footnotetext{
${ }^{5}$ O Portal Capes foi utilizado para buscar trabalhos relacionados. Apenas Claudino (2005) aborda indiretamente o assunto ao realizar uma pesquisa sobre as imagens formadas do leitor a partir do livro didático de língua inglesa. A autora sugere que os LD analisados não auxiliam na formação do cidadão por conter atividades marcadas pela artificialidade.
}

Work. pap. linguíst., 13(1): 40-60, Florianópolis, jan.jun,2012 
do $7^{\circ}$ ano $^{6}$ do Ensino Fundamental (antiga $6^{\mathrm{a}}$ série) ${ }^{7}$. Ambas são coleções de reconhecidas editoras nacionais.

O volume analisado da coleção Keep in Mind foi o livro do professor (doravante KM7), que acompanha um CD. O Quadro 1 mostra como o KM7 está organizado:

Quadro 1: Composição e apresentação do KM7*

\begin{tabular}{|c|c|c|c|}
\hline Qtd. & Título & Descrição & $\begin{array}{l}\mathrm{N}^{\mathrm{o}} \mathrm{de} \\
\text { páginas } \\
\text { por título }\end{array}$ \\
\hline 1 & Apresentação & Carta ao aluno & 1 \\
\hline 1 & Scope and sequence & Sumário & 4 \\
\hline 1 & Welcome & $\begin{array}{l}\text { Três atos: Presentation, Let's practice e Let's write. Recapitula o } \\
\text { conteúdo do ano anterior, apresenta os personagens do livro, } \\
\text { elucida o que os aprendentes já conhecem e sugere a criação de } \\
\text { regras a serem seguidas em sala de aula. }\end{array}$ & 3 \\
\hline 16 & Unit & $\begin{array}{l}\text { Composta de: } \\
\text { Get in the mood-uma introdução à unidade. } \\
9 \text { atos: (1) Presentation, (2) Focus on vocabulary, (3) Let's } \\
\text { practice, (4) Focus on grammar, (5) Let's practice [again], (6) } \\
\text { Let's read, (7) Let's listen, (8) Let's write e (9) Let's talk. } \\
\text { Extra activities } \\
4 \text { caixas de texto: Cool!, Language corner, Food for thought e } \\
\text { Project. }\end{array}$ & 8 \\
\hline 8 & Review & $\begin{array}{l}\text { Formada por: } \\
\text { (1) Vocabulary review, (2) Grammar review, (3) Have fun with } \\
\text { English, (4) Check your progress e (5) Now I can... }\end{array}$ & 2 \\
\hline 4 & Thematic unit & $\begin{array}{l}\text { Formada por: } \\
\text { Get in the mood - uma introdução à unidade } \\
2 \text { atos, cujos enunciados variam de acordo com o tema } \\
\text { Project }\end{array}$ & $\begin{array}{l}3 \text { com } 2 \\
\text { páginas } \\
1 \text { com } 3 \\
\text { páginas }\end{array}$ \\
\hline 1 & Word list & Lista de palavras e seus significados, algumas com figuras & 7 \\
\hline 1 & Language Summary & Resumo gramatical & 3 \\
\hline 1 & Reading & Proposição de leitura de um texto literário & 8 \\
\hline 1 & CD track list & Listagem das faixas do CD & 1 \\
\hline 1 & $\begin{array}{l}\text { Assessoria } \\
\text { Pedagógica }\end{array}$ & $\begin{array}{l}\text { Projeto didático-pedagógico do volume, conteúdo, constituição do } \\
\text { volume, planejamento, orientações pedagógicas, transcrições dos } \\
\text { textos de compreensão oral, bibliografia. }\end{array}$ & 88 \\
\hline
\end{tabular}

*Fonte: quadro criado para a corrente pesquisa.

Igualmente, o volume analisado da coleção Links: English for Teens (doravante LET7) foi o livro do professor, que também acompanha um CD. O Quadro 2 mostra a organização do LET7.

\footnotetext{
${ }^{6}$ A escolha dessas coleções se justifica pelo fato de serem as duas opções de livros para o ensino de língua estrangeira moderna (inglês) disponibilizadas para as escolas públicas. A escolha pelo livro do $7^{\circ}$ ano foi aleatória, haja vista analisar as duas coleções completas estar além do escopo deste trabalho.

${ }^{7}$ Para uma visão geral das duas coleções, vide Brasil (2010).
} 
Quadro 2: Composição e apresentação do LET7*

\begin{tabular}{|l|l|l|l|}
\hline Qtd. & Título & Descrição & $\begin{array}{l}\mathrm{N}^{\circ} \\
\text { páginas } \\
\text { por título }\end{array}$ \\
\hline 1 & Welcome & Carta ao aluno & 1 \\
\hline 1 & Contents & Sumário do conteúdo & 2 \\
\hline 1 & $\begin{array}{l}\text { Characters in the } \\
\text { Spotlight }\end{array}$ & Apresenta os personagens do livro. & 2 \\
\hline 10 & Unit & $\begin{array}{l}\text { Formada por 9 seções: } \\
\text { (1) Let's read!, (2) Let's listen! (3) Let's speak!, (4) Grammar in } \\
\text { Action!, (5) Grammar Notes, (6) Words in Action, (7) Let's Write!, } \\
\text { (8) Let's Play! e (9) Let's Stop and Think! }\end{array}$ & $\begin{array}{l}\text { (exceto } \\
\text { unit } \\
\text { com 12) }\end{array}$ \\
\hline 1 & Workbook & Exercícios suplementares e 4 unidades de revisão (Checkpoints) & 29 \\
\hline 1 & Glossary & Lista de palavras e seus significados & 6 \\
\hline 1 & Extra reading & Lista de sugestões de leitura & $3 / 4$ de 1 \\
\hline 1 & Bibliography & Lista de bibliografia & 1 \\
\hline 1 & $\begin{array}{l}\text { Manual } \\
\text { Professor }\end{array}$ & $\begin{array}{l}\text { Projeto didático-pedagógico do volume, objetivos, constituição do } \\
\text { volume, orientações pedagógicas, sugestões de leitura para } \\
\text { aprofundamento e conteúdo do CD. }\end{array}$ & 32 \\
\hline
\end{tabular}

*Fonte: quadro criado para a corrente pesquisa.

\subsection{Instrumentos}

Para organizar os dados foram utilizados dois checklists, elaborados por esta autora. Os checklists podem ajudar a se alcançar uma análise mais profunda e se ter uma percepção mais detalhada dos conteúdos e atividades ${ }^{8}$ que abarcam a questão da cidadania nos dois volumes.

O Checklist 1, elaborado com base nos assuntos considerados importantes para a formação do cidadão segundo os PCN, já descritos na sessão 2.1 deste artigo, foi utilizado para a verificação dos assuntos referentes à cidadania constantes nos dois livros. Através do Checklist 1, foram angariados dados das 28 unidades compondo o KM7 e das 10 unidades compondo o LET7, num total de 38 unidades. O Checklist 2 foi utilizado para verificar quais atividades constantes em ambos os livros promovem as interações que abrem espaço para a participação discursiva do aprendente, essencial para a sua formação como cidadão. $\mathrm{O}$ Checklist 2 foi criado a partir da fundamentação proposta pelos PCN para o engajamento discursivo por parte do aprendente e também de critérios utilizados em outro checklist (DIAS, 2009), considerados pertinentes para este trabalho ${ }^{9}$. Devido à natureza minuciosa do Checklist 2 e às limitações de tempo e espaço desta pesquisa, este checklist contemplará o levantamento de dados de apenas duas unidades em cada coleção, escolhidas aleatoriamente, quais sejam: LET7, unidades 5 e 6, e KM7, unidades 10 e 11.

\footnotetext{
${ }^{8}$ Neste trabalho, atividades se referem a propostas de prática/uso dos assuntos sendo abordados e procura não tratar das distinções entre exercícios e tarefas.

${ }^{9}$ Por questão de espaço, os checklists serão apresentados apenas no momento da apresentação e discussão dos dados, na seção a seguir.
}

Work. pap. linguíst., 13(1): 40-60, Florianópolis, jan.jun,2012 


\subsection{Questões de Pesquisa}

Os resultados advindos da análise feita com base nos dois checklists serão discutidos e servirão de suporte para responder às seguintes questões de pesquisa:

1. Quais dos assuntos considerados como essenciais pelos PCN para a formação do cidadão são abordados nos dois LD?

2. Quais atividades, que tratam de tais assuntos, promovem o engajamento discursivo do aprendente?

3. Os LD KM7 e LET7 apresentam potencial para auxiliar o professor no objetivo de formar cidadãos?

\section{RESULTADOS E DISCUSSÃO}

Esta seção apresenta os resultados e os discute, buscando responder às questões de pesquisa apresentadas na seção anterior.

Os assuntos considerados como essenciais nos PCN - LE para a formação do cidadão são abordados nos dois volumes, como demonstra o Quadro 3, que apresenta os dados

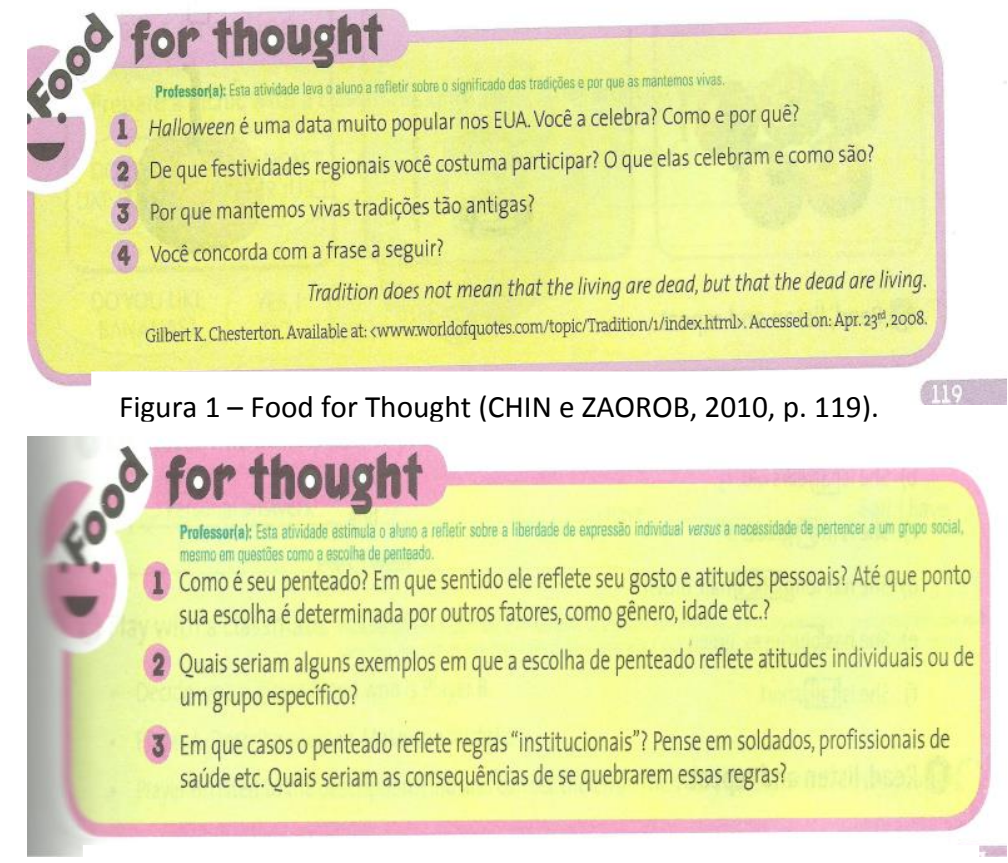

Figura 2 - Food for Thought (CHIN e ZAOROB, 2010, p. 83). angariados a partir dos livros KM7 e LET7. Os dados demonstram que ambos os livros dão margem ao trabalho com a questão de assuntos relacionados ao exercício da cidadania, tais como (1) a conscientização sobre o mundo pluralizado em que se vive, (2) o respeito às diferenças, (3) a preocupação com a saúde, entre outros, em graus de aprofundamento diferentes. Igualmente, ambos os livros deixam de trabalhar os assuntos relacionados com a sexualidade.

O KM7 oferece mais momentos para lidar com a questão da pluralidade cultural do que o LET7 (vide

Critério 1 - Pluralidade Cultural). Segundo os PCN (BRASIL, 1998), a reflexão sobre as diversas culturas e a sua própria cultura promove uma "aceitação das diferenças nas maneiras de expressão e de comportamento" (p. 37), importantes para o agir no mundo social (a título de ilustração, vide Figura 1). Do mesmo modo, o KM7 oferece mais oportunidades para a reflexão sobre a identidade dos aprendentes em interação, ou seja, oportunizam a sua autopercepção e também a percepção do outro (vide Critério 2 - Percepção de suas próprias características, capacidades e limitações e respeito às do outro), importantes para gerar a

Work. pap. linguíst., 13(1): 40-60, Florianópolis, jan.jun,2012 
compreensão sobre a individualidade de cada pessoa, sem preconceitos e rejeições, fundamentais para o convívio em um mundo pluralizado como o atual (como ilustração, vide Figura 2).

Quadro 3: Checklist 1: assuntos importantes para a formação do cidadão de acordo com os PCN

\begin{tabular}{|c|c|c|}
\hline \multirow[t]{2}{*}{ Critérios - assuntos } & \multicolumn{2}{|c|}{ Localização das atividades } \\
\hline & KM7 & LET7 \\
\hline $\begin{array}{l}\text { 1. Pluralidade cultural: } \\
\text { Valores e costumes de outras } \\
\text { culturas e da sua própria cultura }\end{array}$ & $\begin{array}{c}\text { OCR, p. 10; } \\
\text { FT, p. 11; P, p. 17; GM, p. 19; } \\
\text { LR, p. 34; PT, p. 35; GM, p. 47; } \\
\text { C, p. 59; NIC, p. 64; LP, p. 67; } \\
\text { FG, p. 68; EA, p. 72; LP, p. 75; } \\
\text { FT, p. 83; LR, p. 88; FT, p. 97; } \\
\text { NIC, p. 100; GM, FT, p. 119; FT, } \\
\text { p. 133; GM, FT, p. 137; GM, FT, } \\
\text { p. 145; Act 1, p. 162-163 }\end{array}$ & $\begin{array}{c}\text { WA, p. 54; LW, p. 55; LST, p. } \\
109 ;\end{array}$ \\
\hline $\begin{array}{l}\text { 2. Percepção de suas próprias } \\
\text { características, capacidades e } \\
\text { limitações e respeito às do outro } \\
\text { (diferenças, autopercepção, da sua } \\
\text { realidade e percepção do outro) }\end{array}$ & $\begin{array}{l}\text { C, p. 41; FT, p. 43; EA, p. 54; } \\
\text { EA, p. 62; GM, p. 65; FT, p. 65; } \\
\text { LR, 71; PT, p. 71; } \\
\text { FT, p. 83; C, p. 102; FT, p. } 109 ; \\
\text { C, p. 110; GM, p. 127; PT, p. } \\
\text { 143; PT, p. } 164 .\end{array}$ & $\begin{array}{c}\text { LST, p. 17; LST, p. 57; LW, p. } \\
\text { 77; LS, p. } 93 .\end{array}$ \\
\hline $\begin{array}{l}\text { 3. Inglês como língua hegemônica, } \\
\text { desigualdades entre países e grupos } \\
\text { sociais }\end{array}$ & $\begin{array}{l}\text { GM, FT, p. 11; LC, p. 57; GM, } \\
\text { p. } 156 ; \text { Act } 1-2 ; \text { p. } 157 ; \text { PT, p. } 157\end{array}$ & LST, p. 47 \\
\hline $\begin{array}{l}\text { 4. Preocupação com a saúde } \\
\text { (incluindo diversão e segurança) }\end{array}$ & $\begin{array}{l}\text { GM, p. 29; FT, p. 31; GM, p. 55; } \\
\text { FT, p. 61; GM, p. 73; LR e FT, p. } \\
\text { 78; PT, p. 79; GM, FT, p. } 109 ; \\
\text { LR, p. } 115 \text {; Act } 1 \text {, p. } 158 ; \text { Act } 2 \text {, } \\
\text { p. } 159\end{array}$ & $\begin{array}{l}\text { LST, p. 27;LR, p. 28; WA, p. } \\
\text { 34; LW, p. 35; } \\
\text { LST, p. 37; LR, p. 48 e 49; LL, } \\
\text { p. 50; LR, p. } 80 \text { e 81; LS, p. 82; } \\
\text { LP, p. 88; LST, p. 89; }\end{array}$ \\
\hline $\begin{array}{lcr}5 . \quad \text { Trabalho } & \text { e } & \text { consumo: } \\
\text { oportunidades } & \text { e } & \text { questões } \\
\text { relacionadas ao trabalho e consumo } \\
\text { exacerbado }\end{array}$ & $\begin{array}{c}\text { C, p. 102; GM, p. 101; FT, p. 106; } \\
\text { PT, p. 107; FT, p. } 145\end{array}$ & LR, p. 58 e 59; LST, p. 67; \\
\hline $\begin{array}{l}\text { 6. Valorização das relações entre as } \\
\text { pessoas }\end{array}$ & GM, p. 91; LR, p. 142; PT, p. 151 & LL, p. 102; \\
\hline $\begin{array}{l}\text { 7. Respeito aos direitos humanos, } \\
\text { às várias etnias, idosos, portadores } \\
\text { de necessidades especiais, } \\
\text { homossexuais, falantes de uma } \\
\text { variedade não hegemônica }\end{array}$ & $\begin{array}{l}\text { FT, p. 25; } \\
\text { PT, p. 157; }\end{array}$ & $\begin{array}{c}\text { LST, p. 27; LST, p. 17; LST, p. } \\
79 .\end{array}$ \\
\hline $\begin{array}{l}\text { 8. Meio ambiente: preservação do } \\
\text { meio ambiente e respeito aos } \\
\text { animais }\end{array}$ & $\begin{array}{c}\text { Act } 1-2, \text { p. 160; Act } 2, \text { p. } 161 ; \text { PT, } \\
\text { p.161 }\end{array}$ & $\begin{array}{l}\text { LS, p. 73; LR, p. 90; LW, p. } \\
\text { 98; LST, p. 99; }\end{array}$ \\
\hline $\begin{array}{l}\text { 9. Orientação sexual: percepção do } \\
\text { corpo como fonte de prazer e } \\
\text { consciência da pluralidade de } \\
\text { expressão da sexualidade humana }\end{array}$ & & \\
\hline
\end{tabular}

O recurso negrito em alguns dados no quadro indica que essas seções dos LD estudados não propõem o tema diretamente, mas possuem potencial para que isso seja feito, muito embora não haja essa orientação no livro do professor.

Abreviações: $\mathrm{OCR}=$ Our classroom rules; $\mathrm{P}=$ Presentation $; \mathrm{LP}=$ Let's practice $; \mathrm{LC}=$ Language corner $; \mathrm{LW}=$ Let's write; GM = Get in the mood; FT = Food for thought; FV = Focus on vocabulary; C = Cool!; LR = Let's

Work. pap. linguíst., 13(1): 40-60, Florianópolis, jan.jun,2012 
read $;=\mathrm{LL}=$ Let's listen $; \mathrm{LT}=$ Let's talk $; \mathrm{PT}=$ Project $; \mathrm{NIC}=$ Now I can $\ldots \mathrm{LS}=$ Let's Speak! GA $=$ Grammar in Action; GA = Grammar Notes; WA = Words in Action; LP = Let's Play! LST = Let's Stop and Think.

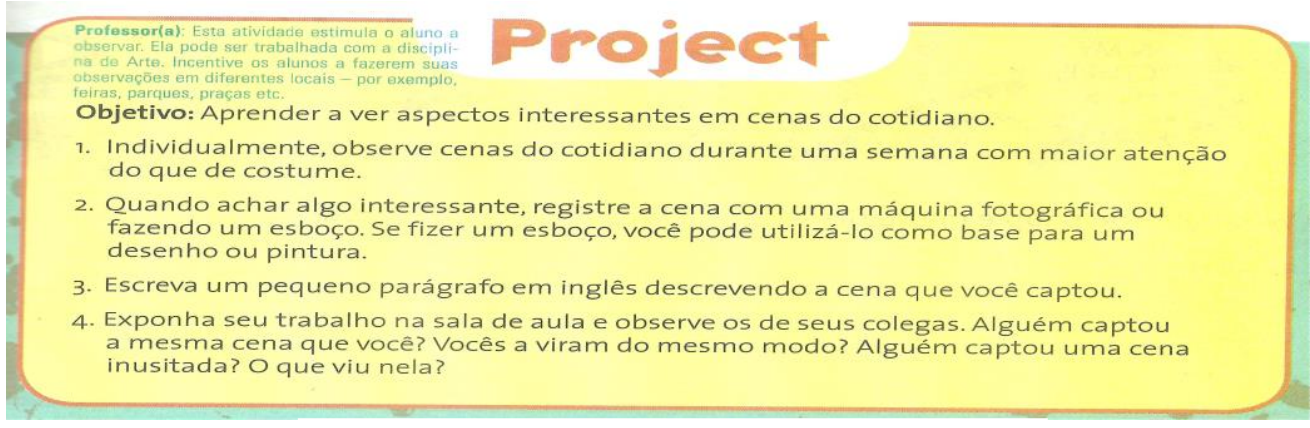

Figura 3 - Project (CHIN e ZAOROB, 2010, p. 143)
Uma comparação entre as colunas do Quadro 3 demonstra que o LET7 parece trazer à tona

os assuntos observados, exceto sobre a orientação sexual, em determinados momentos, através das atividades da Seção Let's Stop and Think, enquanto o KM7 oferece várias outras oportunidades para que um mesmo assunto seja continuamente tratado e, mesmo quando não o trata diretamente, inclui uma atividade que tem potencial para isso ${ }^{10}$. Como é ilustrado pela Figura 3, a atividade propõe que sejam observadas e registradas situações cotidianas. Muitas das situações poderão vir a tratar de
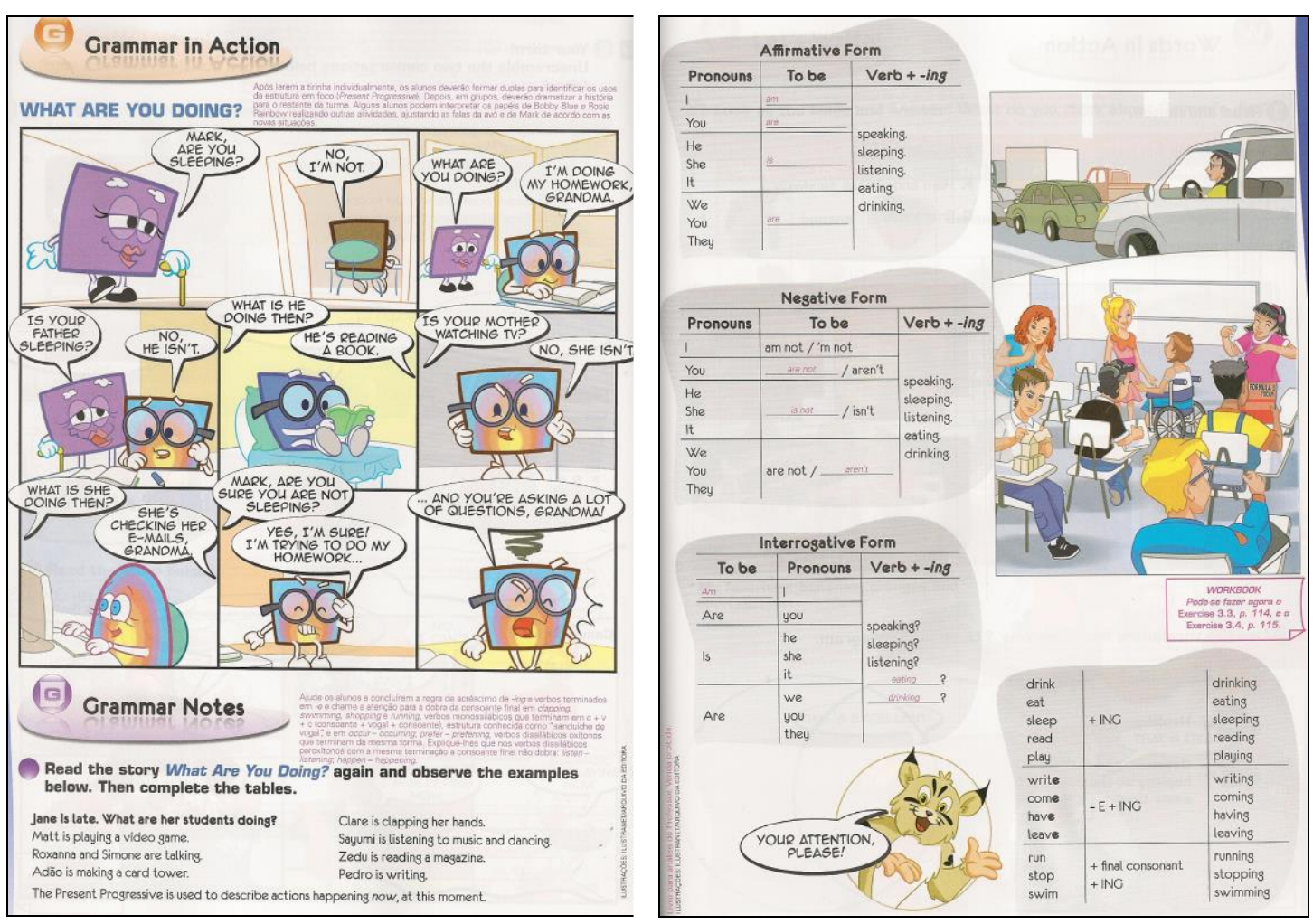

comportamentos e de características de determinadas pessoas, o que pode ser explorado,

${ }^{10}$ Vide ênfases marcadas pelo recurso negrito.

Work. pap. linguíst., 13(1): 40-60, Florianópolis, jan.jun,2012 
durante a exposição dos trabalhos, com a proposição de uma reflexão entre grupos e/ou indivíduos. A exploração do potencial

das diferenças

de atividades como essa depende de como o professor escolhe conduzir a sua aula.

No KM7, muitas das atividades de produção e compreensão tanto escritas quanto orais direcionam e, aos poucos, engajam os alunos na reflexão do tema, foco da unidade. Já, no LET7, o chamado à reflexão é pontual ${ }^{11}$, exceto em unidades cujos temas parecem receber uma abordagem direta, tais como Unit 3 - You are what you eat, com o tema "Saúde lanches saudáveis e não saudáveis", e Unit 6-Fashion Show, com o tema "Consumismo". Mesmo havendo estabelecido de forma direta o tema da Unidade expresso no seu título, quando o objetivo é abordar itens gramaticais, a conexão com o tema inexiste, haja vista os exemplos não terem relação alguma com ele. Tome-se, por exemplo, a Unit 3 - You are what you eat (Unidade 3 - Você é o que come). A Unidade tem como tema a preocupação com a saúde (Critério 4), no entanto, a Seção Grammar in Action, ilustrada na Figura 4, traz explicações e exemplificações do tempo verbal present continuous através de exemplos não relacionados ao tema, tais como a utilização de ações como dormir, fazer deveres, ler e assistir TV. Como a Figura 4 ilustra, a proposta de itens gramaticais é introduzida por uma história. Para maior integração, essas histórias poderiam manter o tema trabalhado na unidade e inserir uma pergunta para uma rápida discussão do seu conteúdo, que poderia ser problematizado pelos participantes da aula de forma crítica.

No que tange à promoção do engajamento discursivo, o Quadro 4 apresenta dados correspondentes a duas unidades de cada volume: LET7, unidades 5 (Free Time) e 6 (Fashion Show) e KM7, unidades 10 (Does he play the drums?) e 11 (Where does your father work?).

Quadro 4: Checklist 2: atividades para a promoção do engajamento discursivo

\begin{tabular}{|c|c|c|}
\hline \multirow[t]{2}{*}{ Critérios } & \multicolumn{2}{|c|}{ Localização das atividades nos livros } \\
\hline & KM7 & LET7 \\
\hline $\begin{array}{l}\text { 1. As atividades oferecem oportunidades para o } \\
\text { desenvolvimento do conhecimento sistêmico } \\
\text { (pronúncia, sintaxe, relação semântica). }\end{array}$ & $\begin{array}{l}\text { P1, p. } 92 ; \text { FV, p. } 93 ; \text { FG, p. } \\
\text { 94; FV, p. } 103 ; \text { FG, p. } 104 ; \\
\text { LC, p. } 105 ; \text { LW, p. } 97 \text { LW, } \\
\text { p. } 107 .\end{array}$ & $\begin{array}{c}\text { LS, p. } 51 ; \mathrm{LL}, \text { p. } 60, G A \mathrm{e} \\
G N, p .63,64 .\end{array}$ \\
\hline $\begin{array}{l}\text { 2. As atividades oferecem oportunidades para o } \\
\text { desenvolvimento do conhecimento de mundo. }\end{array}$ & $\begin{array}{l}\text { GM1, p. 91; P1, p. 92; LR, } \\
\text { p. } 106 .\end{array}$ & $W A, p .54 ; L W 1, p .55$. \\
\hline $\begin{array}{l}\text { 3. As atividades oferecem oportunidades para o } \\
\text { desenvolvimento do conhecimento da } \\
\text { organização textual. }\end{array}$ & $\begin{array}{c}\text { LR, p. 96; GM, p. 101; C, p. } \\
\text { 102; LR, p. } 106 .\end{array}$ & $\begin{array}{l}\text { LR, p. } 48 \text { e } 49 * *, \text { LL, p. } \\
50^{* *}, L W, p .55, \text { LR, p. } 58 \\
\text { e } 59^{* *} .\end{array}$ \\
\hline $\begin{array}{l}\text { 4. As atividades levam o aprendente a refletir } \\
\text { sobre a natureza da linguagem, sobre como ela } \\
\text { funciona e ajudam a desenvolver uma maior } \\
\text { consciência da sua própria língua materna. }\end{array}$ & $\begin{array}{c}\text { GM1, p. 91; P1, p. 92; LC, } \\
\text { p. 93; LP1, p. } 103 .\end{array}$ & LS, p. 51 \\
\hline $\begin{array}{l}\text { 5. As atividades desencadeiam a preocupação } \\
\text { do aprendente em ser compreendido e também } \\
\text { compreender (quando fala ou escreve - } \\
\text { clareza). }\end{array}$ & LC, p. 105; LW, p. 97. & - \\
\hline
\end{tabular}

Figura 4 - Grammar in Action (SANTOS e MARQUES, 2010, p. 32 e 33)

${ }^{11} \mathrm{O}$ chamado à retlexão sobre um determinado assunto não é proposto em outros momentos dentro de uma mesma unidade (Unit), mas apenas na Seção Let's Stop and Think.

Work. pap. linguíst., 13(1): 40-60, Florianópolis, jan.jun,2012 


\begin{tabular}{|c|c|c|}
\hline $\begin{array}{l}\text { 6. As atividades de compreensão escrita } \\
\text { incentivam o uso do conhecimento anterior dos } \\
\text { leitores.* }\end{array}$ & LR2c, p. 96; LR, p. 106. & $\begin{array}{c}\text { LR, p. } 48 \text { e } 49 ; \text { LR, p. } 58 \text { e } \\
59 .\end{array}$ \\
\hline $\begin{array}{l}\text { 7. As atividades de compreensão escrita } \\
\text { permitem a exploração dos aspectos das } \\
\text { condições sob as quais o texto de leitura foi } \\
\text { produzido (quem escreveu, para quem, com } \\
\text { qual propósito, como, de que ponto de vista, de } \\
\text { que lugar social, quando, onde).* }\end{array}$ & LR, p. 96; LR, p. 106. & - \\
\hline $\begin{array}{l}\text { 8. As atividades de produção escrita envolvem } \\
\text { contextos reais e refletem situações de } \\
\text { interlocução para as quais os aprendentes } \\
\text { escrevem no dia a dia.* }\end{array}$ & PT, p. 97. & - \\
\hline $\begin{array}{l}\text { 9. As atividades de produção escrita } \\
\text { especificam as condições para a produção } \\
\text { textual (para quem, de que forma, para qual } \\
\text { propósito, onde o texto será circulado).* }\end{array}$ & PT, p. 97; PT, p. 107. & $L W, p .55$ (parcialmente). \\
\hline $\begin{array}{l}\text { 10. As atividades de produção escrita envolvem } \\
\text { vários estágios como planejamento, rascunho, } \\
\text { revisão por parte dos colegas, reescrita, entre } \\
\text { outros.* }\end{array}$ & $\begin{array}{l}\text { PT, p. } 97 \text { (parcialmente); } \\
\text { PT, p. } 107 \text { (parcialmente). }\end{array}$ & $L W, p .55$ (parcialmente). \\
\hline $\begin{array}{l}\text { 11. As atividades de produção escrita permitem } \\
\text { a produção de textos para circularem } \\
\text { socialmente.* }\end{array}$ & PT, p. 97. & - \\
\hline $\begin{array}{l}\text { 12. As atividades de produção escrita propostas } \\
\text { incentivam os alunos a usarem a Internet, } \\
\text { dicionários, gramáticas, anotações de sala de } \\
\text { aula, para enriquecer a produção escrita.* }\end{array}$ & PT, p. 97; PT, p. 107. & $L W, p .55$. \\
\hline $\begin{array}{l}\text { 13. As atividades de compreensão oral } \\
\text { incentivam o uso do conhecimento anterior dos } \\
\text { ouvintes. }\end{array}$ & LL, p. 96. & LL, p. 50; LL, p. 61. \\
\hline $\begin{array}{l}\text { 14. As atividades de compreensão oral dão } \\
\text { margem à exploração dos aspectos relacionados } \\
\text { à produção do texto oral (quem falou, para } \\
\text { quem, com qual propósito, como, de que ponto } \\
\text { de vista, de que lugar social, quando, onde).* }\end{array}$ & LL, p. 96. & - \\
\hline $\begin{array}{l}\text { 15. As atividades de compreensão oral dão } \\
\text { margem à exploração de aspectos relacionados } \\
\text { à organização textual (ex.: troca de turnos, } \\
\text { repetições, hesitações, contrações, marcadores } \\
\text { do discurso para articular ideias etc).* }\end{array}$ & LL, p. 96. & - \\
\hline $\begin{array}{l}\text { 16. As atividades de produção oral incentivam } \\
\text { o uso do conhecimento anterior dos falantes.* }\end{array}$ & $\begin{array}{l}\text { GM3, p. 91; LP3, p. 105; } \\
\text { LT, p. } 106 .\end{array}$ & LR, p. 58; LST, p. 67. \\
\hline $\begin{array}{l}\text { 17. As atividades de produção oral têm fins } \\
\text { comunicativos diversos (conversas informais, } \\
\text { entrevistas, relatórios orais e com base em } \\
\text { pesquisa feita, debates etc).* }\end{array}$ & $\begin{array}{l}\text { LT, p. 97; LP3, p. } 105 ; \mathrm{LT}, \\
\text { p. } 106 .\end{array}$ & LS, p. 50 e 51; LST, p. 67. \\
\hline $\begin{array}{l}\text { 18. As atividades de produção oral promovem o } \\
\text { desenvolvimento de diferentes habilidades } \\
\text { (atender ao telefone, expressar condolências, } \\
\text { pedir permissão para falar, expressar afeição, } \\
\text { agradecer alguém, oferecer ajuda, } \\
\text { aceitar/recusar um convite etc.).* }\end{array}$ & LT, p. 97; LP3, p. 105. & LS2, p. 51. \\
\hline
\end{tabular}

${ }^{*}$ Critérios com base na ficha produzida pela Professora Reinildes Dias como parte de seu projeto de pesquisa "Avaliando o livro didádito (LD) de língua estrangeira (LE) no contexto do Ensino Fundamental" no programa de Pós-Graduação em Estudos Linguísticos da Faculdade de Letras da UFMG (DIAS, 2009, p. 226-234).

** Os textos não são reais, mas criados especificamente para o trabalho pedagógico.

Work. pap. linguíst., 13(1): 40-60, Florianópolis, jan.jun,2012 
Recursos de ênfase: negrito = atividades que não cumprem o critério, mas têm potencial para isso de acordo com a prática em sala de aula; itálico = atividades que cumprem o critério, mas de forma descontextualizada.

Abreviações $^{12}: \mathrm{P}=$ Presentation; $\mathrm{LP}=$ Let's practice; $\mathrm{LC}=$ Language corner $; \mathrm{LW}=$ Let's write; $\mathrm{GM}=$ Get in the mood; $\mathrm{FT}=$ Food for thought $; \mathrm{FV}=$ Focus on vocabulary; $\mathrm{C}=$ Cool!; $\mathrm{LR}=$ Let's read $;=\mathrm{LL}=$ Let's listen; $\mathrm{LT}=$ Let's talk; $\mathrm{PT}=$ Project $; \mathrm{NIC}=$ Now I can $. . \mathrm{LS}=$ Let's Speak $! \mathrm{GA}=$ Grammar in Action; GA = Grammar Notes; WA = Words in Action; $\mathrm{LP}=$ Let's Play! LST $=$ Let's Stop and Think.

Os dados demonstram que o conteúdo no KM7 não apenas ajuda a desenvolver o conhecimento sistêmico, o conhecimento de mundo e o conhecimento textual dos aprendentes (critérios 1, 2, 3), mas também estimula o uso de tais conhecimentos nas atividades propostas nas várias habilidades (critérios $6,7,9,10,13,14,15$ e 16 - compreensão escrita, produção escrita, compreensão oral e produção oral). $\mathrm{O}$ uso desses conhecimentos é essencial para que o aprendente se engaje discursivamente. É possível perceber, no entanto, que as discussões que promovem a reflexão nas seções Food for Thought são apresentadas em português, o que nos leva a pensar que essas atividades serão realizadas na língua materna e não na estrangeira.

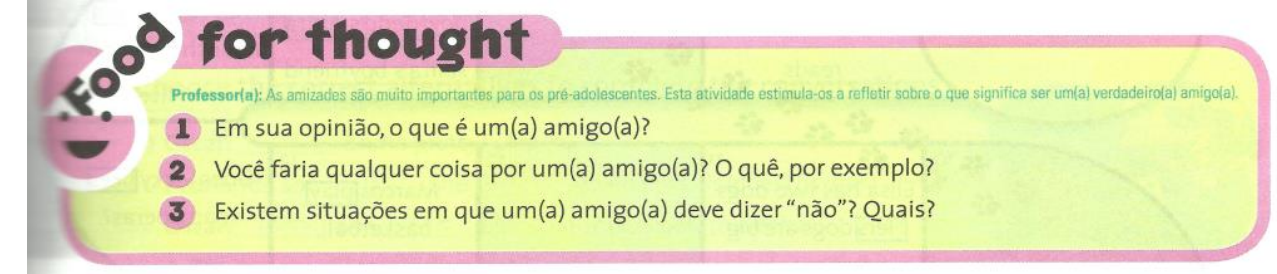

Figura 5 - Food for thought (CHIN e ZAOROB, 2010, p. 97)

Portanto o engajamento discursivo é incitado e realizado em português.

Tem-se, assim, a discussão

sobre temas relacionados à formação do cidadão $n a$ aula de inglês, mas não em inglês, como

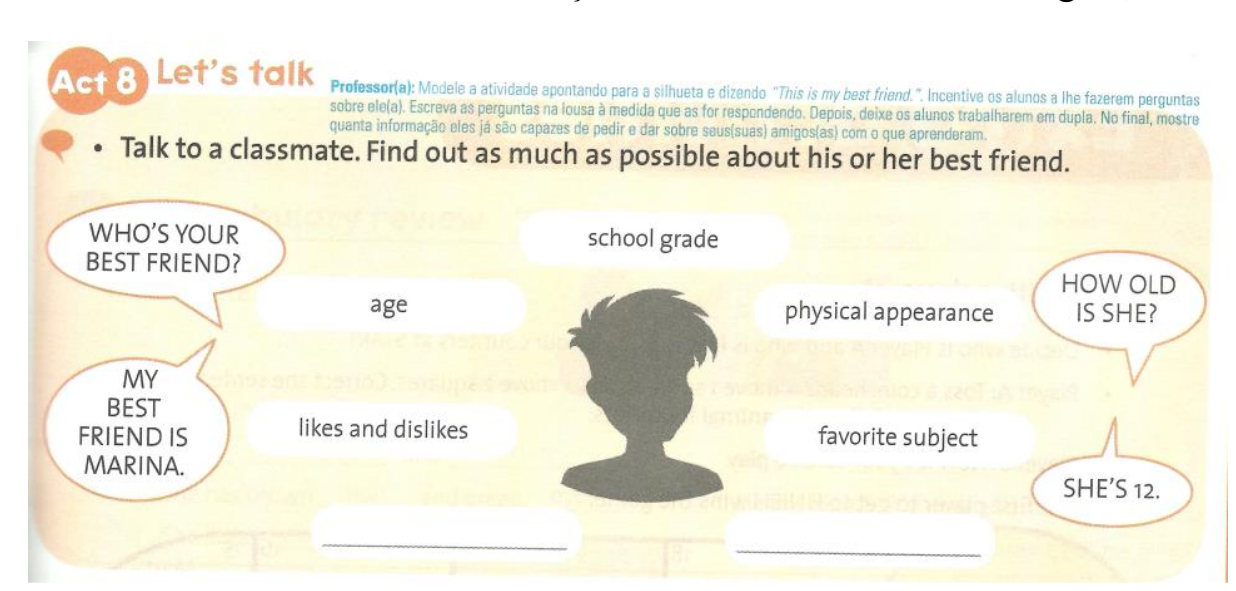

ilustrado na

Figura 5. Em contrapartida, em outros momentos, nos quais há a prática da oralidade de forma mais controlada, os aprendentes utilizam a língua inglesa em Figura 6 - Let's talk (CHIN e ZAOROB, 2010, p. 97) situações que imitam situações reais e que fazem com que eles se engajem no discurso, como se vê na Figura 6. Ela ilustra uma atividade propondo a interação entre dois aprendentes a fim de conversarem sobre os seus melhores amigos, assunto comum no círculo social.

\footnotetext{
${ }^{12}$ Quando números são acrescentados às abreviações, significa que dentro daquela seção apenas o item ao qual o número corresponde é relevante. GM3, por exemplo, indica que na seção Get in the mood! Apenas a atividade 3 é relevante para o critério.
}

Work. pap. linguíst., 13(1): 40-60, Florianópolis, jan.jun,2012 
Outro aspecto presente nas atividades é a proposta da reflexão sobre a linguagem, sobre o seu uso nos diferentes textos apresentados e a ênfase na natureza da linguagem como prática social (critério 4). Em consonância com essa reflexão, em sua maioria, as atividades se utilizam de dados do mundo real (critérios 3, 8, 11, 12), principalmente as de compreensão e produção escrita. No KM7, os textos de compreensão escrita são textos de gêneros variados e circulam no meio social ${ }^{13}$. O trabalho com tais textos viabiliza uma conexão da sala de aula e a linguagem como prática social. Isso permite ao aprendente perceber que a linguagem da sala de aula não é "um mundo de faz de conta" (vide Figura 7). As produções textuais dos aprendentes têm a possibilidade de circularem socialmente, o que enfatiza essa relação com a prática social (vide Figura 8). As atividades de compreensão oral não parecem trazer textos originais, mais lidam com assuntos do dia a dia (como comprar presentes) e se utilizam de dados reais, como ilustrado pela Figura 9 (as opções de livros para presente são títulos disponíveis no mercado).

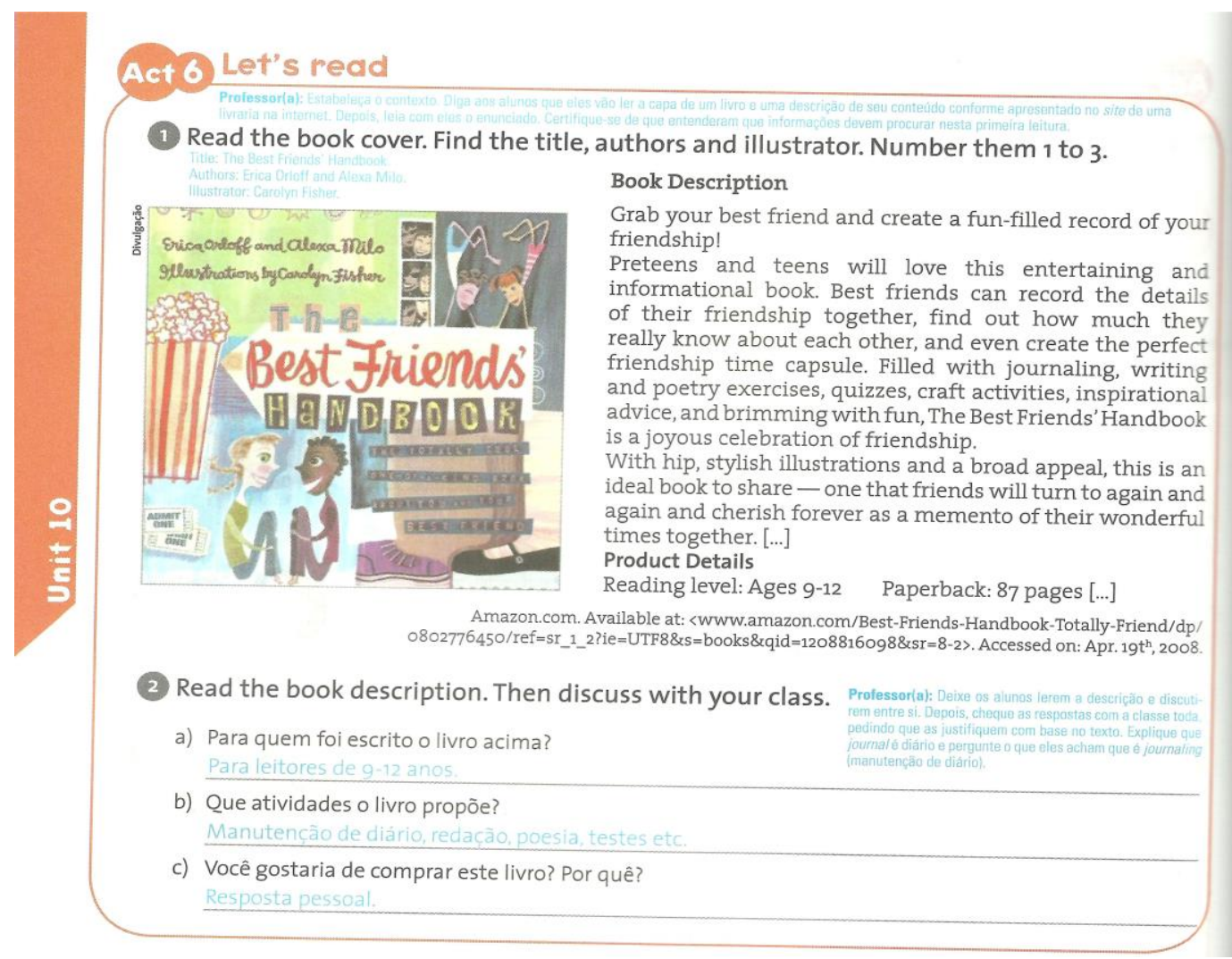

Figura 7 - Let's read (CHIN e ZAOROB, 2010, p. 96)

\footnotetext{
${ }^{13}$ Todas as referências das Unidades analisadas foram conferidas e encontradas por meio da Internet.
}

Work. pap. linguíst., 13(1): 40-60, Florianópolis, jan.jun,2012 


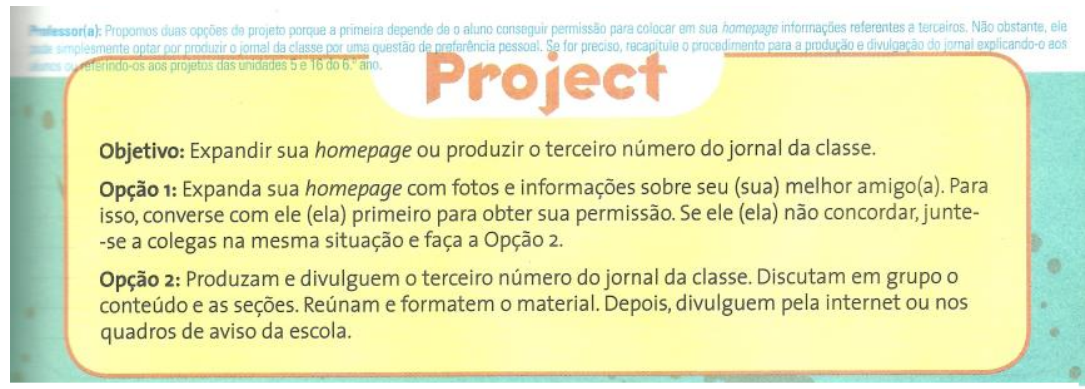

Figura 8 - Project (CHIN e ZAOROB, 2010, p. 97)

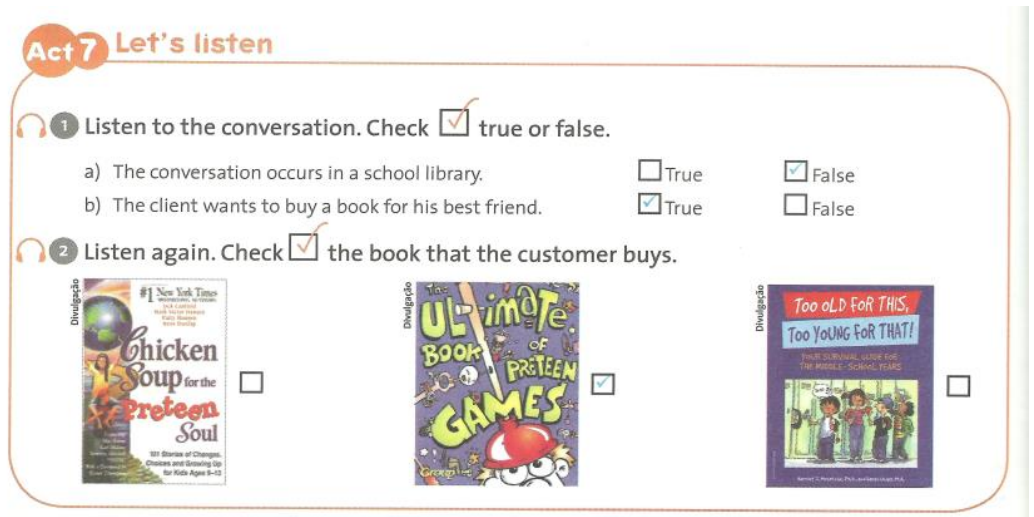

Figura 9 - Let's listen (CHIN e ZAOROB, 2010, p. 96)
Ao se engajarem nas atividades mencionadas, referentes aos critérios $3,4,6,7,8$, $9,10,11,12,13,14,15 \mathrm{e}$ 16, os aprendentes refletem sobre e exercitam ações do mundo real, praticando atos importantes para a sua autopercepção,

organização e convívio social, importantes para a sua formação como cidadão (BRASIL, 1998).

Com relação ao

LET7, o Quadro 4 demonstra que há atividades que se destinam a desenvolver o conhecimento sistêmico, o conhecimento de mundo e o conhecimento de organização textual dos

aprendentes. No entanto, elas aparecem de forma reduzida e/ou descontextualizada. Tome-se como exemplo as atividades propostas na Seção Grammar in Action, que traz um pouco de conhecimento sistêmico. Nessa seção, a organização gramatical é explicada com o uso de

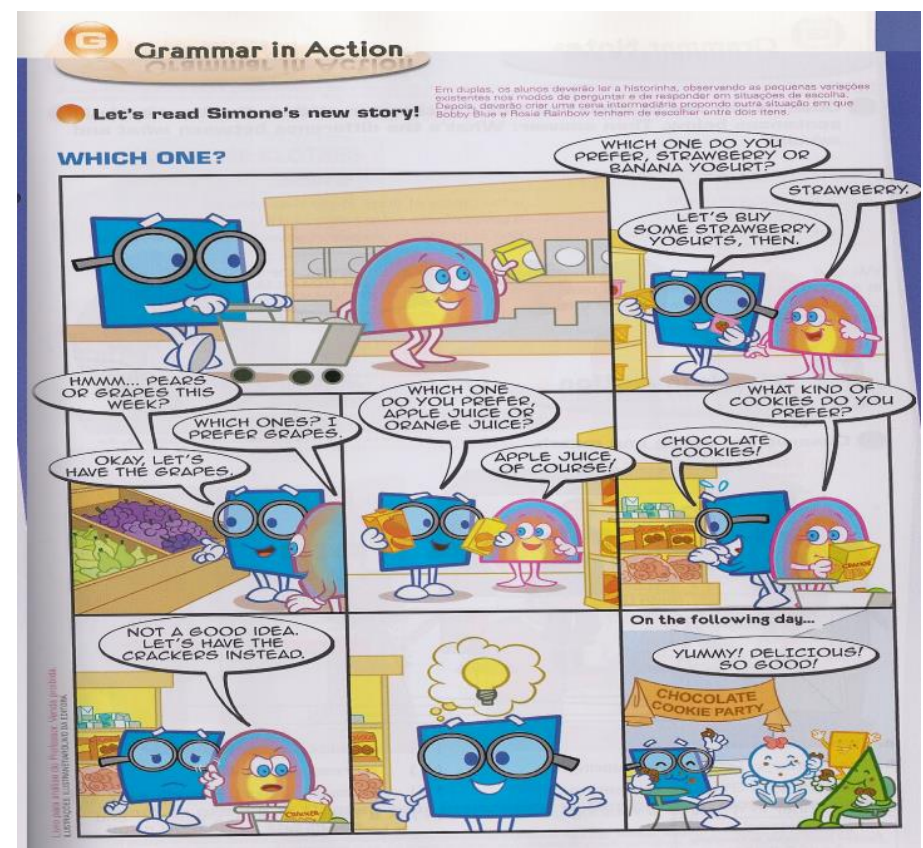

Figura 10 - Grammar in Action (SANTOS e MARQUES, 2010, p. 63) exemplos que não fazem parte daquele tema sendo tratado na unidade (preferência por determinadas roupas e o consumismo), como ilustrado pela Figura 10. O mesmo acontece com a Seção Grammar Notes, que se segue à seção Grammar in Action. A Seção Grammar Notes, por sua vez, inclui países, cores, cinema e não elementos que auxiliem na Seção Let's Stop and Think, atividade na qual refletirão sobre a questão do consumismo. Há a ausência de tais elementos também na Seção Let's Write (vide Figuras $11 \mathrm{e}$

Work. pap. linguíst., 13(1): 40-60, Florianópolis, jan.jun,2012 


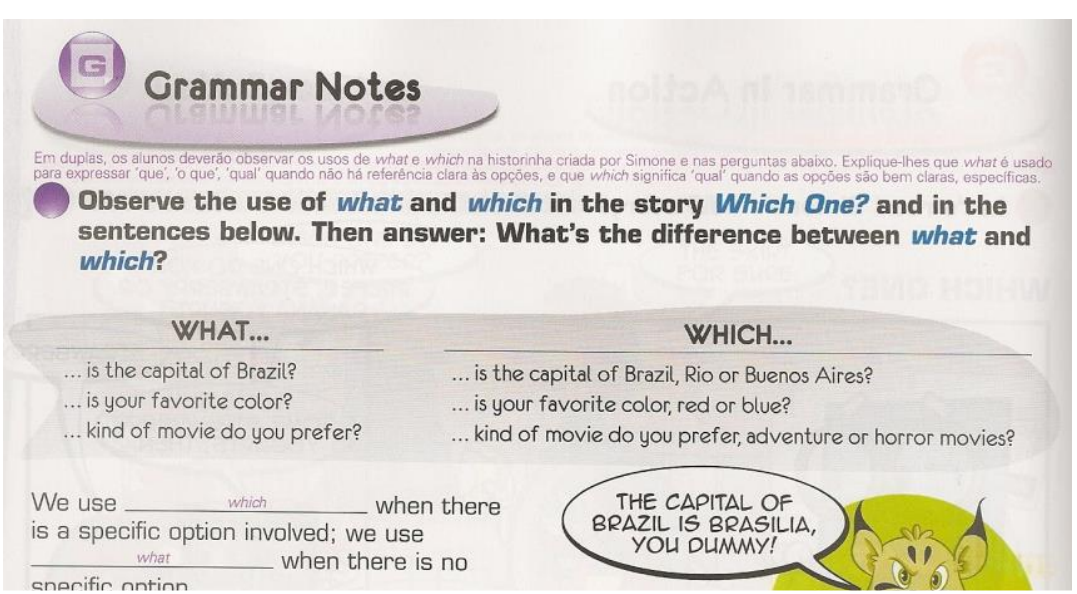

Figura 11 - Grammar Notes (SANTOS e MARQUES, 2010, p. 64)

12).

Embora os textos que compõem as várias atividades não sejam autênticos e não explorem as condições sob as quais foram produzidos (critérios 7 e 14), eles lidam com assuntos que circulam no mundo social. A Seção Let's Listen (vide Figura 13), por exemplo, traz $\mathrm{o}$
respeito da qualidade de resultado de um pretenso levantamento realizado em Edimburgo a respeito da qualidade de
vida dos jovens, trazendo à tona atividades que possuem potencial para serem realizadas também pela comunidade que compõe a sala de aula. A partir disso, o professor tem

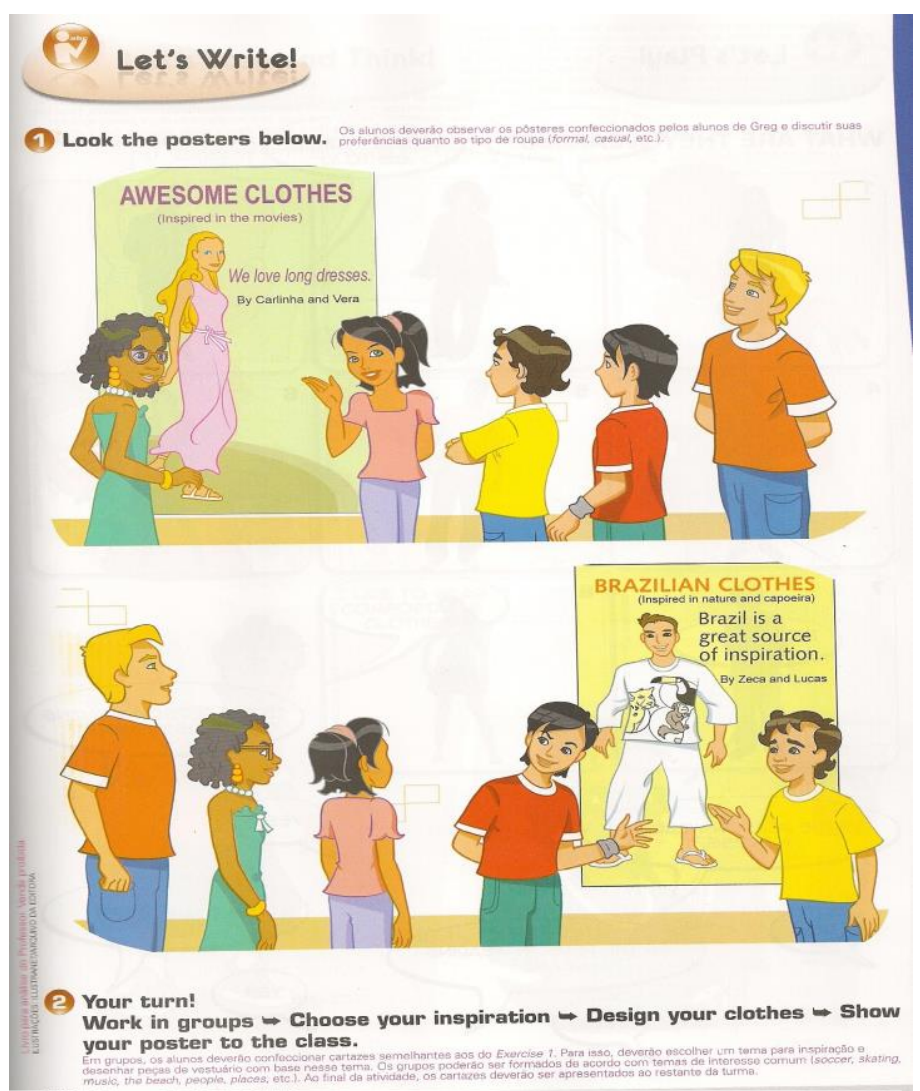

Figura 12 - Let's Write (SANTOS e MARQUES, 2010, p. 65) condições para promover uma reflexão por parte dos aprendentes acerca de suas próprias atividades, auxiliando-os a se engajarem discursivamente (critérios 6 e 16).

Em contrapartida, as atividades propostas no LET7 nem sempre permitem uma interação com relevância social entre os aprendentes, ou seja, a forma como a atividade é apresentada nem sempre impulsiona a participação discursiva. A Seção Let's Speak (vide Figura 14), por exemplo, pede que dois aprendentes falem com Roxanna, uma personagem do livro, fazendo perguntas sobre suas preferências. Saber as preferências de um personagem irreal não parece ser tão significativo quanto perguntar sobre as preferências do outro envolvido na interação, preferências que devem ser respeitadas para um bom convívio social.

$$
\text { Além dos aspectos }
$$

mencionados acima, como ilustra a

Figura 12, as produções escritas dos aprendentes, propostas na seção Let's Write! não cogitam a possibilidade de circulação em meios sociais reais, exceto o da sala de aula (critérios 8 e 11). Essa falta de relevância para a circulação social além dos domínios da sala de aula pode prejudicar o engajamento discursivo do aprendente. $\mathrm{O}$ modo como o(a) professor(a) vai lidar

Work. pap. linguíst., 13(1): 40-60, Florianópolis, jan.jun,2012 


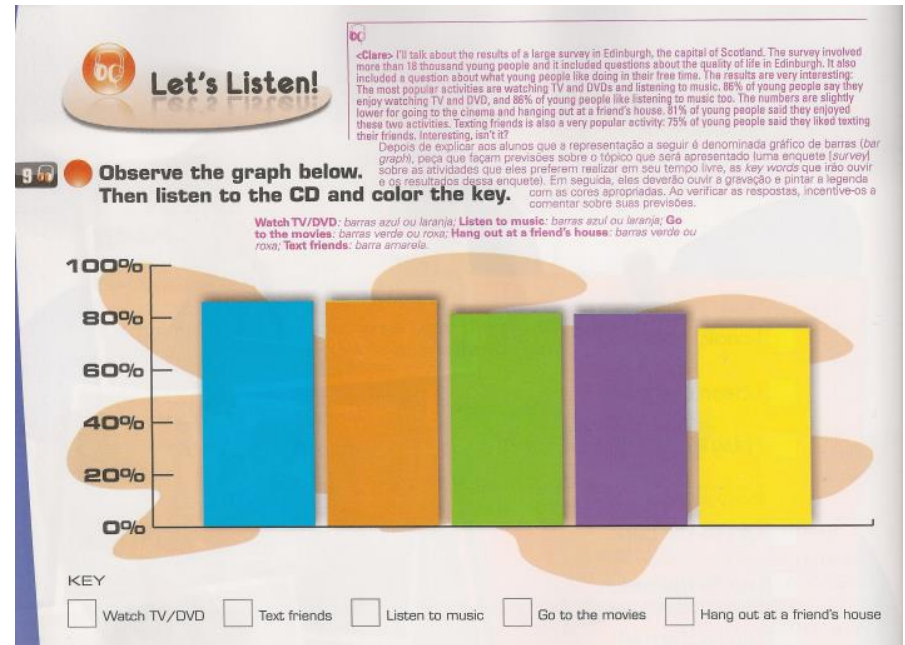

Figura 13 - Let's Listen! (SANTOS e MARQUES, 2010, p. 50)

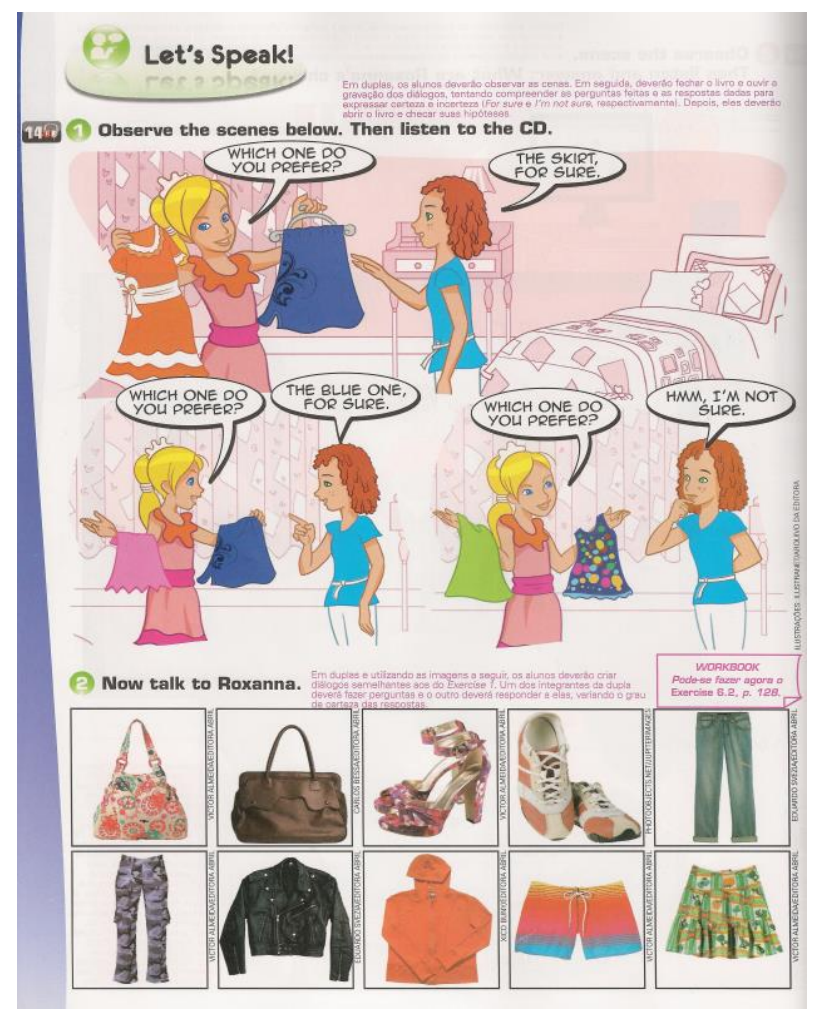

com esse material em sala de aula pode, no entanto, potencializar as atividades, fazendo adaptações e inserções que podem contribuir para o desenvolvimento da formação do aluno como cidadão.

Em suma, os dados indicam que ambos os livros possuem, em níveis diferentes de aprofundamento, a presença (1) de assuntos que fomentam a formação do cidadão e (2) de atividades que promovem ações como o engajamento discursivo para essa formação. Em outras palavras, de um modo geral e de maneiras distintas, os LD KM7 e

LET7 apresentam potencial para auxiliar o professor no objetivo de formar cidadãos. No entanto, corroborando a análise constante no Guia PNLD 2011 (BRASIL, 2010), que propõe orientações pedagógicas complementares para as duas coleções (mais numerosas, porém, para a Links: English for Teens), esta pesquisa aponta também a necessidade de intervenções por parte do(a) professor(a), principalmente para a prática em sala de aula com o LET7 a fim de otimizar as atividades sem potencial direto para promover a formação do cidadão. A seção a seguir tece considerações finais que incluem as implicações deste trabalho e indicações para pesquisas futuras.

Figura 14 - Let's Speak! (SANTOS e MARQUES, 2010, p. 62)

\section{CONSIDERAÇÕES FINAIS}

Durante a análise dos dados, surgiram outros fatores relevantes, como, por exemplo, o planejamento sugerido no livro do professor para o KM7. O livro sugere que o conteúdo de cada unidade seja trabalhado em até quatro aulas de 50min. Minha experiência como

Work. pap. linguíst., 13(1): 40-60, Florianópolis, jan.jun,2012 
professora me faz supor que isso não seja possível, pela gama de atividades e pela densidade que cada unidade possui. Ainda que o Project seja realizado como tarefa extraclasse (homework), é necessário tempo para a proposição da atividade e para o seu desfecho, seja para a sua apresentação para o grupo, seja para demonstração de como o projeto foi veiculado socialmente. Talvez 6 aulas sejam suficientes, dependendo do rendimento e participação do grupo em cada unidade. Não oferecer tempo para a participação efetiva do aprendente, ao meu entender, é perder a oportunidade de deixá-lo crescer e participar ativamente como cidadão no mundo social trazido à sala de aula. $\mathrm{O}$ (a) professor(a) utilizando o MK7 tem em mãos meios consistentes para o(a) auxiliar na formação do cidadão, principalmente se não ceder à pressão de cumprir todas as unidades dentro do mesmo ano letivo.

Quanto à questão da consciência da pluralidade cultural, autopercepção e percepção do outro, conduzindo ao respeito das diferenças, essenciais para o convívio do cidadão em um mundo social pluralizado como o atual, o LET7 traz situações, principalmente nas seções gramaticais Grammar in Action e Grammar Notes (CHIN e ZAOROB, 2010, p. 32, p. 43, p. 52, p. 63) que evidenciam contra-posturas: falta de paciência, irritação, deboche e desconsideração. O livro do professor e as dicas para a sala de aula não dão sugestões para que se fale sobre o assunto. Portanto, cabe aos professores problematizarem essas questões, discutindo se tais posturas veiculadas naquelas seções são as que o cidadão deve tomar para viver em sociedade. O próprio personagem do livro utiliza a palavra "dummy" (bobo) para se digirir ao aprendente (vide Figura 11) e não há orientações de como se lidar com isso, podendo colaborar para a ocorrência de bullying em sala de aula.

A discussão realizada nesta pesquisa bem como essas considerações finais podem contribuir para a reflexão do(a) professor(a) que adotar esses LD, fazendo um convite a um olhar para as atividades mencionadas de modo mais crítico, com a possibilidade de potencializar e multiplicar as possibilidades de situações favoráveis à formação do cidadão.

Pesquisas futuras podem, ainda, investigar a adequação do material a várias classes sociais, sem privilégio à classe média e/ou à alta (um exemplo: figuras com fotos retiradas de canais da TV fechada - tipo TV a cabo - são veiculadas nos LD. Supõe-se que a classe baixa, a priori, tem acesso à TV aberta somente). Além disso, estudos futuros podem verificar como as dicas e os diálogos entre LD e aprendente são realizados: são diálogos que respeitam a realidade do aprendente no seu processo de aprender? Por exemplo, após a apresentação de uma regra gramatical, um dos personagens dos LD analisados diz que 'nunca se esquece'. Levando em consideração que o personagem atua como um tipo de modelo, sua fala implica que o aprendente não pode se dar o direito de esquecer ou cometer falhas na atividade subsequente.

Finalmente, concordo com Pinto e Pessoa (2009) ao afirmar que "mesmo que um LD se apresente de forma perfeitamente adequada [ou não] aos novos parâmetros educacionais, a prática do professor no contexto de sala de aula é fundamental para o processo de ensino/aprendizagem de LE" (PINTO e PESSOA, 2009, p. 96) (inclusão minha). Tendo isso em vista, pesquisas futuras podem investigar como o professor lida com os itens mencionados neste trabalho em sua prática em sala de aula para contribuir com o processo de construção do aluno como cidadão.

Work. pap. linguíst., 13(1): 40-60, Florianópolis, jan.jun,2012 


\section{REFERÊNCIAS}

BORTONI-RICARDO, S.M. O professor pesquisador: introdução à pesquisa qualitativa. São Paulo: Parábola Editorial, 2008.

BRASIL. Lei $\mathrm{n}^{\mathrm{o}}$ 9.394, de 20 de dezembro de 1996. Estabelece as diretrizes e base da educação nacional. In. Diário da União, ano CXXXIV, n. 248, 23.12.96.

O Guia de Livros Didáticos - PNLD 2011: Língua Estrangeira Moderna. Brasília: Secretaria de Educação Básica, 2010.

.Secretaria de Educação Fundamental. Parâmetros Curriculares Nacionais: Língua Estrangeira. Terceiro e Quarto Ciclos do Ensino Fundamental. Brasília: MEC/SEF, 1998.

CHIN, E. Y.; ZAOROB, M. L. Keep in Mind. $7^{\circ}$ Ano. Língua Estrangeira Moderna. São Paulo: Scipione, 2010.

CLAUDINO, B. C. V. A. Investigando o livro didático de língua inglesa: imagens de leitor. 2005. 107f. Dissertação (Mestrado em Letras). Universidade Federal da Paraíba. João Pessoa, 1995. Disponível em <http://www.dominiopublico.gov.br/download/texto/cp123852.pdf $>$. Acesso em: 10 de dezembro de 2010.

DHnet. Direitos Humanos. O que é cidadania. Disponível em $<$ http://www.dhnet.org.br/direitos/sos/textos/oque_e_cidadania.html $>$. Acesso em: 2 de dezembro de 2010.

DIAS, R. Critérios para a avaliação do livro didático (LD) de língua estrangeira (LE). In. DIAS, R.; CRISTÓVÃO, V. L. (Org.). O livro didático de língua estrangeira: múltiplas perspectivas. Campinas: Mercado de Letras, 2009, p. 199-234.

JOHNSON, K. E. Understanding communication in second language classroom. RICHARDS, Jack C. (editor). Cambridge: Cambridge University Press, 1995.

MAGNO E SILVA, W. Livros didáticos: fomentadores ou inibidores da automatização? In. DIAS, R.; CRISTÓVÃO, V. L. (Org.). O livro didático de língua estrangeira: múltiplas perspectivas. Campinas: Mercado de Letras, 2009, p. 57-78.

PEREIRA, P. V. S. O ato de ler: uma análise da prática da leitura em disciplinas do ensino médio. 2007. 158 f. Dissertação (Mestrado em Educação)-Universidade de Brasília, Brasília, 2007.2 Disponível em $<\underline{\text { http://repositorio.bce.unb.br/bitstream/10482/3778/1/2007_Patr\%c3\%adciaVieiradaSilvaPer }}$ eira.pdf>. Acesso em: 9 de dezembro de 2010.

PINTO, A. P; PESSOA, K. N. Gêneros textuais: professor, aluno e o livro didático de língua inglesa nas práticas sociais. In. DIAS, R.; CRISTÓVÃO, V. L. (Org.). O livro didático de língua estrangeira: múltiplas perspectivas. Campinas: Mercado de Letras, 2009, p. 79-97.

RAMOS, R. C. G. O livro didático de língua inglesa para o ensino fundamental e médio: papéis, avaliação e potencialidades. In. DIAS, R.; CRISTÓVÃO, V. L. (Org.). O livro 
didático de língua estrangeira: múltiplas perspectivas. Campinas: Mercado de Letras, 2009, p. 173-198.

SANTOS, D.; MARQUES, A. Links: English for Teens. $7^{\circ}$ ano. Língua Estrangeira Moderna. São Paulo: Ática, 2010.

VIEIRA, L. Cidadania e globalização. 8. ed. Rio de Janeiro: Record, 2005, p. 22-32.

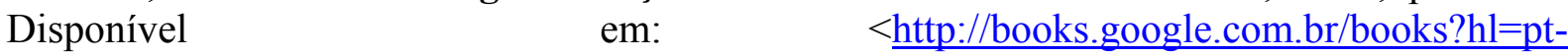
BR\&lr $=\& i d=S 064 e N k 6 C y Y C \& o i=$ fnd $\& p g=P A 9 \& d q=$ conceito + de + cidad $\% \mathrm{C} 3 \%$ A3o\&ots $=\mathrm{xI}$ tSX6J9kT\&sig=7FX2Eu a8r5pHMGCuc63asA4LBk\#v=onepage\&q=conceito $\% 20 \mathrm{de} \% 20 \mathrm{cid}$ ad\%C3\%A3o\&f=false $>$. Acesso em: 8 de dezembro de 2010 .

Work. pap. linguíst., 13(1): 40-60, Florianópolis, jan.jun,2012 